\title{
Scoring Model in Operational Research on Cultural-Tourism: A Case Study in Kota Kinabalu, Sabah
}

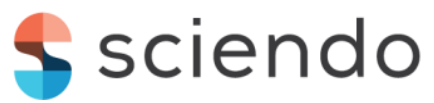

Thavamalar Ramamoortya, Noraini Abdullahb, Suzelawati Zenian ${ }^{b}$

a Centre of Postgraduate Studies, Universiti Malaysia Sabah, 88400 Kota Kinabalu Sabah, Malaysia

b Faculty of Science and Natural Resources, Universiti Malaysia Sabah, 88400 Kota Kinabalu Sabah, Malaysia

*Corresponding Author Email: malarneka_malar@yahoo.com

\section{DOI: 10.2478/pjg-2020-0004}

\begin{abstract}
:
The predominant culture of Sabah consists of a motley of cultures, each of which has been brought in by the different ethnic groups from their indigenous cultures. The total population of Sabah consists of more than thirty different ethnicities and races, and the number of languages and dialects go over eighty. Hence the cultural tourism in Sabah would have varied criteria that can be looked into. The aim of this paper is to use the scoring model in operational research to rank these decision criteria according to highest scores. The preferability of tourist visiting these hot spots is done by ranking their preferability based on a weightage. Highly scored attraction factors would attract more tourists to visit cultural spots in Kota Kinabalu. Therefore, these would help operational managers in the tourism industry to focus on promoting and marketing this sector.
\end{abstract}

Keywords: Indigenous, ethnicities, cultural tourism, tourist

\subsection{Introduction:}

In the current years, tourism and hospitality industry has shown a deepening diversifies development and have become one of the industries that contributes the most in economic development as well as a quick growing industry internationally. A researcher stated that this industry had been one of the main noteworthy services in the earth [1]. In fact, the evolution of tourism is rising all over the world particularly in Malaysia, a developing country. Therefore, tourism has been generating income and an extremely important industry in Malaysia. The government has taken effective initiatives to attract people to visit local places in Malaysia. Tourism report of 2010 says Malaysia was going to be the second most visited country in Asia after China [2] According to Malaysian Tourism data, 31.8 million tourists have visited Malaysia in 2017.

Tourism is the main tool in promoting cultural and heritage in a way that cultural factors are the significant point representing a country. Cultural tourism covers all the traveling aspects whereby people travel to educate tourist with each other's living ways, their beliefs with thoughts [3]. Furthermore, tourism theoreticians agree to the oldest "birth certificates" of tours on culture which includes the explorations by ancient Greeks and Romans as well as academic aspect [4]. Hence, cultural tourism is namely the earliest type of tourism because of the rising growth of interest in culture in recent decades. In early of 1980s cultural tourism has been accepted independently from recreational tourism. According to a study, researcher defined cultural tourism as a form of special importance and observational tourism established on the search for or participation in new and deep cultural understanding of an aesthetic, cultural reports of a cultured, intellectual, emotional or psychological nature [5].

Previous researcher suggested an extensive definition of cultural tourism: "visits by using men and women from out of doors the host network inspired thoroughly or in component via hobby in the historic, inventive, scientific or lifestyle/historical past services of the historic, inventive, scientific or lifestyle/historical past services of a network, area or group" [6]. As a result, cultural destinations can include sites as diverse as museums, gala's, architecture, heritage, and visitor sights associated with food, language, and faith [7]. Some researcher cautioned exceptional definitions of cultural tourism [8]. His conceptual definition refers to "the movement of men and women to cultural attractions away from their ordinary vicinity of house, with a view to gather new records and reports to meet their cultural needs" while the technical definition states "all moves of humans to specific cultural points of interest, inclusive of history websites, creative and cultural manifestations, arts and drama outside their regular vicinity of house" [8].

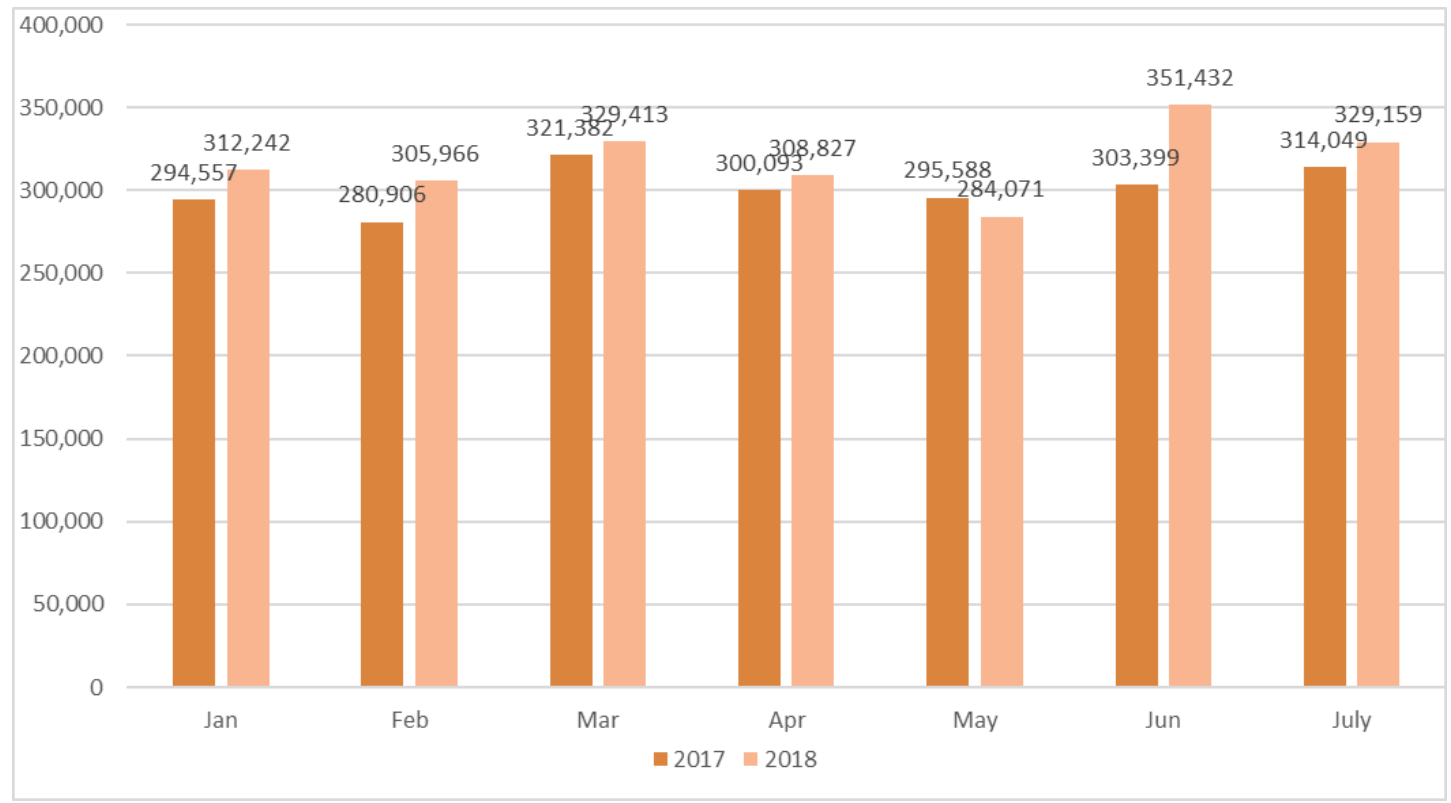

Figure 1: Sabah Visitors Arrivals Statistics from January to July 2017 and 2018 [9,10].

\subsection{Materials and Methods}


The data for this research been collected at four main tourist locations which were Mari-Mari Cultural Villa, Sabah State Museum, Monsopiad Cultural Village and KDCA cultural village. 50 tourists have been selected randomly at each location as respondent respectively, and a total of 200 questionnaires has been collected for this research. Each respondent has been tested respondent validity by preparing similar questions to the same respondent in order to check the respondent validity before proceeding with data analysis [11]. Based on a study, researchers may have given a questionnaire on a similar concept, to determine if the result were connected, as one would expect [11]. Or researcher may have given a questionnaire on a various concept, to determine if the results were the alternative. This refers to the questionnaires ability to measure the concept adequately. once questionnaires are measuring something conceptual or theoretical, researches also necessary to determine its construct validity. About 30 respondents selected randomly for the initial distribution of the questionnaire as the pilot test. The alpha Cronbach value was determined by using the following formulation [12]:

$\hat{\alpha}=\frac{k}{k-1}\left(1-\frac{\sum_{i=1}^{k} p_{i}\left(1-p_{i}\right)}{\grave{\alpha}_{x}^{2}}\right)$

Where,

$\mathrm{k}=$ number of variables

$p_{i}=$ proportions of the respondents who answered variable $\mathrm{i}$

$\hat{\alpha}_{x}^{2}=$ sample variance of a total population

The nearest value of $\alpha$ to 1.00 , the higher the consistency, and the more efficient the instrument used. Thus, we were using the alpha value of 0.60 as the minimum acceptable reliability test [13]. According to a study, Multi-Criteria Decision-Making (MCDM) may be a decision-making technique that has been applied in varied disciplines like operational research, management, and engineering [14]. Criteria and attributes are used interchangeably and represent varied factors or views that become the premise of analysis of the things thought of. The adoption of the MCDM technique helps to enlighten and organize the decision-making method by aiding decision-makers to pick out the most effective product supported many criteria. Other than that, an MCDM downside will be simply expressed in an exceedingly matrix type that is thought because of the cell matrix. Suppose there are $m$ alternatives to be evaluated below $n$ attributes or criteria.

Then, every component within the matrix, $\mathrm{x}_{\mathrm{i} j}$, represents the standard value of factor $\mathrm{i}$ below attribute $\mathrm{j}$ for $\mathrm{c}=1, \ldots, \mathrm{m}$ and $\mathrm{j}=1, \ldots, \mathrm{n}$. Finding the composite score for every factor or in different words constructing the index will be solved by the MCDM ways. it's typically done by combining the attributes' weights and the attributes' quality of the alternatives. several ways are out there to derive the weights of the factors like the Analytic Hierarchy method (AHP), CRITIC, and using expert information [15-17]. Besides that, there are several MCDM ways which will be applied to try and do the composition like Simple Additive Weighting (SAW) or Scoring Model, the technique for order preference by similarity to ideal resolution (TOPSIS), ELECTRE, and AHP [18,19]. The SAW technique has been applied within the Intelligent Learning atmosphere (ILE) in relation to the performance of the ILE [20]. The technique has conjointly been used in measure and examination the general competitiveness of Taiwan's 5 major domestic airlines corporations [21].

The SAW technique that is additionally called the Weighted Linear Combination or the scoring method could be easy and the most frequently used for the multi-attribute decision technique. the tactic relies on a weighted average. associate degree evaluation score is calculated for every alternative by multiplying the scaled value given to the choice of a particular attribute with the weights of the attributes followed by the summing of the product for all the attributes. This total is called the index and it may be used to evaluate every alternative. The composition is feasible once the weights of the criteria are obtained and the data are normalized. The composition offers us weight to every factor and is calculated using SAW and it may be written mathematically as follows [22]:

$S=\sum_{j=1}^{n} W Z$

where:

$$
\begin{aligned}
& \mathrm{w}_{j}=\text { weight for the criteria } j, \\
& \mathrm{z}_{i j}=\text { rating for criterion } i \text { and decision alternative } j \\
& S_{i}=\text { score for decision alternative } j
\end{aligned}
$$

There are five steps involved during this simple Weighted scoring technique. Step one refers to identify and list main criteria to fulfil interests, enhance advantages or achieve goals. Step two involves in define the weight for each requirement based on its importance to achieve the goals. Step three to see a score for each alternative based on the degree it satisfies the need. Step four to calculate a weighted score for each alternative by multiplying alternative score with requirement weight. And finally, rank alternatives from highest score to lowest score and interpret the results [23]. To outline the importance scale to weight the requirements. the most important requirement to achieve the goal receives higher weight, and the least important receives a lower weight as shown in Table 1.

Table 1: Shows the Weightage to weight the requirements [23].

\begin{tabular}{|l|l|}
\hline Weight & Importance \\
\hline 1 & Very unimportant \\
\hline 2 & Somewhat unimportant \\
\hline 3 & Average important \\
\hline 4 & Somewhat Important \\
\hline 5 & Very Important \\
\hline
\end{tabular}


While to assess every alternative against each requirement all the alternatives are going to be given rating according to its satisfaction level at each tourist spots based on each criterion. If the alternatives absolutely satisfy the requirement, it receives a higher score. On the opposite hand, if the alternatives don't satisfy the requirements, it receives a lower score as shown in table 2.

Table 2: Shows the Rating based on Satisfaction Level [23].

\begin{tabular}{|l|l|}
\hline Rating & Level of Satisfaction \\
\hline 1 & Extremely low \\
\hline 2 & Very low \\
\hline 3 & Low \\
\hline 4 & Slightly low \\
\hline 5 & Average \\
\hline 6 & Slightly high \\
\hline 7 & High \\
\hline 8 & Very high \\
\hline 9 & Extremely high \\
\hline
\end{tabular}

A Weighted Scoring Model (WSM) is the WSM score of the best alternative, $N$ is the number of decision criteria, $a i j$ is the actual value of the $i$ th alternative in terms of the $j$ th criterion, and $w j$ is the weight of the $j$ th criterion. The corresponding aij values and the relative weights for this research to be as follows in Table 3 [24]:

Table 3: Shows Values for Criteria of this research [24].

\begin{tabular}{|l|l|l|l|l|l|}
\hline & Alternative & \multicolumn{4}{l|}{} \\
\hline Criteria & Weightage, wj & $\begin{array}{l}\text { Mari - Mari Cultural } \\
\text { Village }\end{array}$ & $\begin{array}{l}\text { Sabah State } \\
\text { Museum }\end{array}$ & $\begin{array}{l}\text { Monsopiad Cultural } \\
\text { Village }\end{array}$ & KDCA Cultural Villa \\
\hline Destination & 5 & 9 & 8 & 5 & 8 \\
\hline Benefits & 3 & 7 & 6 & 4 & 8 \\
\hline Activity & 4 & 6 & 7 & 7 & 9 \\
\hline Safety & 2 & 8 & 8 & 6 & 8 \\
\hline Services & 2 & 7 & 8 & 6 & 9 \\
\hline
\end{tabular}

\subsection{Results and Discussions}

In this research, tourist became our focus in order to identify and rank the best Cultural spot in Kota Kinabalu, Sabah. A total of 234 tourists been chosen randomly as respondents at Mari- Mari Cultural Village, Sabah State Museum, Monsopiad Cultural Village and KDCA Cultural Villa unfortunately only 200 respondents been accepted for this research due to respondent validity test as said by [11]. Table 4 shows Respondents Demographic Analysis Results.

Table 4: Tourist distribution based on Socio-demographic factors [24].

\begin{tabular}{|c|c|c|}
\hline Demographic Factors & Frequency, f & Percentage, $\%$ \\
\hline \multicolumn{3}{|l|}{ Nationality } \\
\hline Malaysian & 96 & 48 \\
\hline Non-Malaysian & 104 & 52 \\
\hline \multicolumn{3}{|l|}{ Age } \\
\hline Less than 18 years old & 11 & 5.5 \\
\hline $18-30$ years old & 97 & 48.5 \\
\hline $31-40$ years old & 45 & 22.5 \\
\hline $41-50$ years old & 24 & 12 \\
\hline $51-60$ years old & 15 & 7.5 \\
\hline More than 60 years old & 8 & 4 \\
\hline \multicolumn{3}{|l|}{ Gender } \\
\hline Male & 103 & 51.5 \\
\hline Female & 97 & 48.5 \\
\hline \multicolumn{3}{|l|}{ Marital Status } \\
\hline Married & 123 & 61.5 \\
\hline Single & 77 & 38.5 \\
\hline \multicolumn{3}{|l|}{ Higher Education Achieved } \\
\hline High School / Pre- University & 31 & 15.5 \\
\hline Degree & 101 & 50.5 \\
\hline Masters & 35 & 17.5 \\
\hline
\end{tabular}




\begin{tabular}{|c|c|c|}
\hline PHD & 33 & 16.5 \\
\hline \multicolumn{3}{|l|}{ Employment Status } \\
\hline Full time & 71 & 35.5 \\
\hline Part-time & 14 & 7 \\
\hline Unemployed & 19 & 9.5 \\
\hline Self-employed & 59 & 29.5 \\
\hline Retired & 13 & 6.5 \\
\hline Student & 24 & 12 \\
\hline \multicolumn{3}{|l|}{ Monthly income } \\
\hline Less than 1000 & 10 & 5 \\
\hline $1000-2000$ & 28 & 14 \\
\hline $2000-3000$ & 70 & 35 \\
\hline More than 3000 & 102 & 51 \\
\hline \multicolumn{3}{|l|}{ Purpose of Travelling } \\
\hline Business & 21 & 10.5 \\
\hline Visiting Friends and Family & 21 & 10.5 \\
\hline Educational & 36 & 18 \\
\hline Relaxation & 42 & 21 \\
\hline Holiday & 71 & 35.5 \\
\hline Medical & 9 & 4.5 \\
\hline \multicolumn{3}{|c|}{ The frequency of Travelling (a month) } \\
\hline $1-2$ times & 76 & 38 \\
\hline $3-5$ times & 53 & 26.5 \\
\hline $6-10$ times & 19 & 9.5 \\
\hline More than 10 times & 2 & 1 \\
\hline \multicolumn{3}{|c|}{ Motivation in Choosing Places for Travelling } \\
\hline Ecotourism & 57 & 28.5 \\
\hline Cultural Tourism & 143 & 71.5 \\
\hline
\end{tabular}

Table 4 above presented the Tourists distribution based on socio-demographic factors, namely nationality, age, gender, marital status, higher education achievement, employment status, monthly income, the purpose of traveling, frequency of traveling and motivation in choosing places for traveling. Most of the respondents were Non-Malaysian tourist, representing 104 respondents (52\%) out of 200 respondents while others are Malaysian tourists. Most of the respondents were from the age group of 18 to 30 years old (48.5\%), then followed by age group of 31 to 40 years old (22.5\%), 41 to 50 years old (12\%), 51 to 60 years old ( $7.5 \%)$, less than 18 years older ( $5.5 \%)$ and more than 60 years old ( $4 \%$ ).

In terms of gender, most of the respondents are male, which was $51.5 \%$ of the total respondents where the rest are female (48.5\%). $61.5 \%$ of the respondents were married and another $38.5 \%$ of respondents were single. Around $50.5 \%$ of tourists had a degree, $17.5 \%$ of tourist had masters, another 16.5\% had a Ph.D. while another 15.5\% just had higher schools/pre-university certificates of SPM and STPM. 35.5\% of tourist are full-time employees, $29.5 \%$ were self-employed, $12.0 \%$ were students, $9.5 \%$ were unemployed, another $7.0 \%$ were part-time employees and $6.5 \%$ were retired from work. In terms of monthly income, most of the respondents earning more than $3000(51.0 \%), 35.0 \%$ of respondents have the income of $2000-3000$ per month, while $14.0 \%$ of respondents earning 1000 - 2000 per month and only $5.0 \%$ earning less than $1000.35 .5 \%$ of respondents choosing Kota Kinabalu as holiday tourist spot, while another $21.0 \%$ of respondents choose Kota Kinabalu for relaxation, some of the respondents came to Kota Kinabalu for educational purposes (18.0\%), while $10.5 \%$ visiting Kota Kinabalu for business and visiting friends and family purposes and another $4.5 \%$ of respondents came to Kota Kinabalu for medical purposes.

Around $38.0 \%$ of tourists travel 1 to 2 times a month to Kota Kinabalu, $26.5 \%$ of tourists travel 3 to 5 times a month, while $9.5 \%$ of tourist travel 6 to 10 times a month and another $1.0 \%$ of tourist travel more than 10 times a month in Kota Kinabalu, Sabah. 71.5\% of this tourist mainly comes to Sabah to explore the culture while another $28.5 \%$ of tourist came to Sabah for exploring the Ecotourism. It was because these tourists will be guided by the Tour guide and they will take tourist spots in a package where those packages include one or two cultural spots at nearby places. Therefore, some tourist visits cultural spot even though their focus was ecotourism. The questionnaire has been statistically analysed by foremost distributing the questionnaire as a pilot test therefore on verify its reliability. Cronbach's Alpha is the preferred index that provides a measure of the extent to that the things on a test, every of that might be thought of as a mini-test provide consistent data with reference to students' mastery of the field [25].

Table 5: Cronbach alpha values [13].

\begin{tabular}{|l|l|l|l|}
\hline \multicolumn{4}{|l|}{ Reliability Statistics } \\
\hline & Cronbach's Alpha & N of Items & N of respondents \\
\hline Pilot study & 0.966 & 74 & 30 \\
\hline Total survey & 0.994 & 74 & 200 \\
\hline
\end{tabular}

Cronbach alpha values were found to vary per the number of respondents who participated in the pilot test, wherever the information from the questionnaires of 30 respondents had a Cronbach alpha of 0.966 that then raised by 0.028 to 0.966 for the 200 respondents of total data collected. Therefore, each Cronbach values are more than 0.60, and the values of Alpha were nearer to 1.00. Thus, each Cronbach Alpha value were found to be reliable, and the questionnaire might be used and trusty for distribution. In this research, Weighted Scoring Models been used in ranking best cultural tourist spots based on criteria. By using formulation (2), the highest scoring for each alternative been calculated as shown in table 6. 
Table 6: Weighted Scoring Models Results.

\begin{tabular}{|c|c|c|c|c|c|c|c|c|c|}
\hline \multirow[b]{2}{*}{ Criteria } & \multirow[b]{2}{*}{$\begin{array}{l}\text { Requirement } \\
\text { weight, wj }\end{array}$} & \multicolumn{2}{|c|}{$\begin{array}{l}\text { Mari-Mari Cultural } \\
\text { Village }\end{array}$} & \multicolumn{2}{|c|}{ Sabah Museum } & \multicolumn{2}{|c|}{$\begin{array}{l}\text { Monsopiad Cultural } \\
\text { Village }\end{array}$} & \multicolumn{2}{|c|}{$\begin{array}{ll}\text { KDCA } & \text { Cultural } \\
\text { Village } & \end{array}$} \\
\hline & & $\begin{array}{l}\text { Score } \\
\text { (Zij) }\end{array}$ & $\begin{array}{l}\text { Weighted } \\
\text { Score (Wj x } \\
\text { Zij) }\end{array}$ & $\begin{array}{l}\text { Score } \\
\text { (Zij) }\end{array}$ & $\begin{array}{l}\text { Weighted } \\
\text { Score (Wj x } \\
\text { Zij) }\end{array}$ & $\begin{array}{l}\text { Score } \\
\text { (Zij) }\end{array}$ & $\begin{array}{l}\text { Weighted } \\
\text { score (Wj x } \\
\text { Zij) }\end{array}$ & $\begin{array}{l}\text { Score } \\
\text { (Zij) }\end{array}$ & $\begin{array}{l}\text { Weighted } \\
\text { Score (Wj x } \\
\text { Zij) }\end{array}$ \\
\hline Destination & 5 & 9 & 45 & 8 & 40 & 5 & 25 & 8 & 40 \\
\hline Benefits & 3 & 7 & 21 & 6 & 18 & 4 & 12 & 8 & \\
\hline Activities & 4 & 6 & 24 & 7 & 28 & 7 & 28 & 9 & 34 \\
\hline Safety & 2 & 8 & 16 & 8 & 16 & 6 & 12 & 8 & 16 \\
\hline Services & 2 & 7 & 14 & 8 & 16 & 6 & 12 & 9 & 18 \\
\hline \multicolumn{2}{|l|}{ Total, $\mathbf{S i}$} & & 120 & & 118 & & 89 & & 134 \\
\hline \multicolumn{2}{|l|}{ Ranking } & \multicolumn{2}{|l|}{2} & \multicolumn{2}{|l|}{3} & \multicolumn{2}{|l|}{4} & \multicolumn{2}{|l|}{1} \\
\hline
\end{tabular}

Based on Table 6, the best cultural spots determined and ranked according to the highest total score. The weighted score for each criterion been calculated by times requirement weight with a score for each alternative. After obtaining the weighted score for each criterion, all the weighted score will be adding up together to find the total score, $\mathrm{Si}$ as follows [22]:

Total Score, Si Mari-Mari Cultural Village $=\sum \mathrm{wj}(\mathrm{Zij})$

$$
=5(9)+3(7)+4(6)+2(8)+2(7)
$$

$=45+21+24+16+14$

$=120$

From table 6 above, the KDCA Cultural Village the obtained highest score, which was 134 and become most popular Cultural spots thus it's been ranked in $1^{\text {st }}$ place, followed by Mari-Mari Cultural Village with a total score of 120 and been ranked in $2^{\text {nd }}$ place, the Sabah State Museum ranked at $3^{\text {rd }}$ place with a total score of 118 and at $4^{\text {th }}$ place Monsopiad Cultural Village with a total score of 89. Note that the tourists satisfied at KDCA Cultural Village rank first in 4 out of 5 criteria compared to only 1 out of 5 criteria for the Mari-Mari Cultural Village. Therefore, if the weights of the criteria are considered also KDCA Cultural Village will become the best decision alternative as well.

\subsection{Conclusions}

This paper attempts to identify the best Cultural spots in Kota Kinabalu, Sabah by using Weighted Scoring Model (WSM). Results found out that KDCA Cultural Village is best Cultural spot destination because it satisfied all the criteria given. The strategic geographical location of the KDCA Cultural Village has become one of the factors that affect tourist's attraction to KDCA Cultural Village due to its short distance from the Kota Kinabalu International Airport (KKIA). Other than that, the management does provide accommodations such as Homestays to the tourists where the tourists can choose what kind of Cultural homestay they wanted. In terms of benefits, the tourists will be given exposure about all ethnics in Sabah at KDCA by providing traditional attires for every ethnic, foods based on ethnics, traditional performances, and games at each traditional house according to the ethnics, included all as in one package.

\subsection{Acknowledgement}

The authors would like to thank the administration of Universiti Malaysia Sabah (UMS) for funding this research partially under the fundamental research Grant Scheme (GUG0243-1/2018).

\section{References}

[1] H.J. Schumacher, “Let's Talk Europe: Ecotourism”, Business World, Pp. 6, 2007.

[2] World Travel and Tourism Council (WTTC). "Malaysia: Travel and Tourism Climbing to New Heights”, London: World Travel and Tourism Council, 2006.

[3] Roday, Sunetra, Biswal, Archana, J. Vandana, “Tourism Operations and Management third ed”, New Dehli: Oxford University Press, Pp. 173, 2009.

[4] V.R.A. Mikos, and K. Turystyka, “Fenomen, potencjał, perspektywy, GWSHM Milenium”, Gniezno, 2008.

[5] Y. Reisinger, “Tourist-Host contact as a part of cultural tourism World Leisure \& Recreation”, Vol. 36, pp. 24-28, 1994.

[6] T. Silberberg, "Cultural tourism and business opportunities for museums and heritage sites", Tourism Management, Vol. 16, pp. 361-365, 1995.

[7] T.S. Lambert, “Gazing from home: Cultural tourism and art museums Annals of Tourism Research”, Vol. 38, pp. 403-421, 2011.

[8] G. Richards, "Cultural Tourism in Europe Cooper, C.P. and Lockwood, A. (eds) Progress in Tourism”, Recreation and Hospitality Management, Vol. 5, pp. 99-115, 1993.

[9] Sabah Tourism. “Visitor Statistics”, Sabah Tourism Website, 2017.

[10] Sabah Tourism. “Visitor Statistics”, Sabah Tourism Website, 2018.

[11] S.S. Ajay, "Common Procedures for Development, Validity and Reliability of a Questionnaire", International Journal of Economics, Commerce and Management, Vol. 5, pp. 790-801, 2017.

[12] C.S. Wells, and J.A. Wollack, "An Instructor's Guide to Understanding Test Reliability", Testing \& Evaluation Services University of Wisconsin, 2003. 
[13] J.C. Nunnally, and J.H. Bernstein, “Psychometric Theory third ed (Pittsburgh: RWS Publications), 1994.

[14] R. Catalan, and B. Perez, "Evaluation of 3D scanners to develop virtual reality applications Electronics", Robotics and Automotive Mechanics Conference (CERMA 2007), pp. 551-556, 2007.

[15] T.L. Saaty, “Eigenvector and logarithmic least squares European”, Journal of Operational Research, Vol. 48, pp. 156-60, 1990.

[16] D. Diakoulaki, G. Mavrotas, and L. Papayannalis, "Determining objective weights in multi criteria problem: the critic method Computer and OR”, Vol. 22, pp. 763-770, 1995.

[17] S.K. Cheng, "Development of fuzzy multi criteria decision making support system for municipal solid management", (Canada: University of ReginaSaskatchewan), 2000.

[18] E. Triantaphyllou, B. Shu, S. Sanchez, and T. Ray, "Multi-criteria decision making: An operations research approach", Encyclopedia of Electrical and Electronics Engineering, Vol. 15, Pp. 175-86, 1998.

[19] K. Yoon, and C. Hwang, “Multiple attribute decision making: An introduction”, London: Sage Publications, 1995.

[20] K. Kabassi, and M. Virvou, "Personalised adult e-training on computer use based on multiple attribute decision making Interacting with Computers", Vol. 16, pp. 115-32, 2004

[21] Y. Chang, and C. Yeh, “Evaluating airline competitiveness using multiattribute decision making Omega”, Vol. 29, pp. 405-415, 2001.

[22] M.K. Maznah, I. Haslinda, and S.B. Mahmoud, "Multi-Criteria Decision Making Methods For Determining Computer Preference", Index Journal of ICT, Vol. 10, pp. 137-48, 2011.

[23] A. Alireza, M. Majid, and M.Y. Rosnah, "Simple Additive Weighting Approach to Personnel Selection Problem", International Journal of Innovation, Management and Technology, Vol. 1, pp. 511-515, 2010.

[24] S. Bangweon, and K. Seokjoong, "A Method of Assigning Weights Using a Ranking and Nonhierarchy Comparison", Hindawi Publishing Corporation Advances in Decision Sciences, pp. 1-10, 2016.

[25] A.O. Bolarinwa, "Principles and Methods of Validity and Reliability Testing of Questionnaires Used in Social and Health Science Researches", Nigerian Postgraduates Medical Journal, Vol. 22, pp. 195-201, 2018. 